DOI 10.37882/2223-2982.2021.06-2.18

\title{
ИССЛЕДОВАНИЕ АНТРОПОМОРФНОЙ И ПРИРОДОМОРФНОЙ МЕТАФОР В РОМАНЕ И. С. ТУРГЕНЕВА «ОТЦЫ И ДЕТИ» И ИХ ПЕРЕВОДАХ НА АНГЛИЙСКИЙ И НЕМЕЦКИЙ ЯЗЫКИ
}

\section{STUDY OF ANTHROPOMORPHIC AND NATUREMORPHIC METAPHORS IN THE NOVEL BY I.S. TURGENEV "FATHERS AND SONS" AND THEIR TRANSLATIONS INTO ENGLISH AND GERMAN}

I. Kurbanov I. Furzikov

Summary: One of the most controversial issues in linguistics and artistic discourse is the classification of conceptual metaphors by Russian and foreign scientists, the methods of their translation into foreign languages, as well as stylistic and linguoculturological features of the translation of metaphors. This article considers the issue of preserving the conceptual model, the emotional image of the metaphor, the relevance of achieving equivalence along with translation transformations. The research material is the novel by Ivan Sergeevich Turgenev "Fathers and Sons", which is one of the fundamental works of the school curriculum. We will undertake a detailed analysis of the most popular types of conceptual metaphors in cognitive linguistics: anthropomorphic and naturemorphic metaphors, closely related to each other in the novel.

Keywords: discourse, conceptual analysis, metaphorical model, anthropomorphic metaphor, naturemorphic metaphor.

\author{
Курбанов Ибрагим Алиевич \\ К.филол.н., профессор, Сургутский \\ государственный университет \\ ibragimkurbanov@mail.ru \\ Фурзиков Илья Евгеньевич \\ Сургутский государственный университет \\ llya_furzikov@mail.ru
}

Аннотация: Одним из наиболее спорных вопросов в лингвистике и художественном дискурсе является классификация концептуальных метафор отечественными и зарубежными учеными, способы их перевода на иностранные языки, а также стилистические и лингвокультурологические особенности интерпретации метафор. В данной статье рассматривается вопрос сохранения концептуальной модели, эмоционального образа метафоры, релевантность достижения эквивалентности наряду с переводческими трансформациями. В качестве материала исследования выступает роман Ивана Сергеевича Тургенева «Отцы и дети», являющийся одним из фундаментальных произведений школьной программы. Мы предпримем попытку подробного анализа наиболее популярных видов концептуальных метафор в когнитивной лингвистике: антропоморфной и природоморфной метафор, тесно связанных между собой в романе.

Ключевые слова: дискурс, концептуальный анализ, метафорическая модель, антропоморфная метафора, природоморфная метафора.
Д ля дискурса не существует единого определения, которое бы охватывало все сферы его употребления, в связи с чем данный термин можно считать многозначным. Вероятно, что данное явление способствовало его широкому распространению, и дискурс стал рассматриваться многими учеными.

Построение концептуальной базы дискурса происходит путем анализа фреймов и концептов дискурса, которые связывают человека, культуру и язык, а также метафорических моделей, стереотипных и идеологических особенностей, которые лежат в базе направленности носителя языка. Лингвисты и ученые, занимающиеся когнитивным анализом дискурса основываются на том, что во время действия в дискурсе личность представляется как субъект восприятия дискурса, так и субъект его создания, незамедлительно обрабатывающий данные в двух направлениях.

Наше исследование посвящено сопоставительному изучению концептуальной антропоморфной и приро- доморфной метафор, сохранению их моделей при переводе и переводческим трансформациям. Для описания их особенностей необходимо изучить такое понятие как «концепт» - структуру данных для представления стереотипной ситуации.

Согласно определению, данному в «Кратком словаре когнитивных терминов», концепт - это «термин, служащий объяснению единиц ментальных или психических ресурсов нашего сознания» [3, с. 120].

Художественный концепт зачастую содержит в себе несколько понятий и представлений. Он анализируется как единица индивидуального сознания, авторской концептосферы, вербализованная в едином тексте творчества писателя [8, с. 77].

Базовым методом рассмотрения концептов является концептуальный анализ, который делает возможным восстановление всех представлений и знаний, подразумевающихся в имени. Помимо этого, термин «концепту- 
альный анализ» может восприниматься по-разному. С.Е. Никитина подчеркивает неоднозначность выражения данного метода исследования: «само словосочетание «концептуальный анализ» двусмысленно: оно может обозначать и анализ концептов, и определенный способ исследования, а именно анализ с помощью концептов или анализ, имеющий своими предельными единицами концепты в отличие, например, от семантических признаков в компонентном анализе» [7, с. 80-81].

В нашем исследовании мы будем опираться на традиционную классификацию способов и приемов перевода метафор, предложенную Т.А. Казаковой и содержащую: полный перевод, добавление (опущение), функциональную замену, структурное преобразование, традиционное и вариантное соответствие [2, с. 145-146].

Одной из базовых классификаций метафоры, рассмотренной в рамках когнитивной теории метафоры, является классификация, предложенная Дж. Лакоффом и М. Джонсоном. Согласно их теории, «...метафора пронизывает всю нашу повседневную жизнь и проявляется не только в языке, но и в мышлении и действии. Наша обыденная понятийная система, в рамках которой мы мыслим и действуем, метафорична по своей сути» [6, с. 35].

По мнению Дж. Лакоффа и М. Джонсона, метафоризация основана на взаимодействии структуры «источника» (опыт человека) и структуры «цели» (знание), то есть на опыте взаимодействия человека и окружающего мира. Дж. Лакофф и М. Джонсон выделяют два типа метафор, рассматриваемых относительно времени и пространства [6]:

1. Онтологические метафоры. Это тип метафор, позволяющий воспринимать действия и события.

2. Ориентационные метафоры. Метафоры, связанные ориентацией в пространстве и оппозициями типа «верх - низ», «внутри - снаружи», «передняя сторона - задняя сторона», «глубокий - мелкий».

Действительно, если мы обратим внимание на классическую теорию концептуальной метафоры Лакоффа и Джонсона, то увидим, что концептуальные структуры, через которые осуществляется категоризация действительности, имеют вид тождества или формулы, например: «СПОР - это ВОЙНА». Эта особенность встречается и В теории метафорического моделирования, на которую мы будем опираться при анализе антропоморфной и природоморофной метафор.

В настоящее время проблеме метафорического моделирования посвящено большое количество публикаций и научных разработок. В данной статье мы также пользовались исследованиями Курбанова И.А. [4, 5].

Вышеописанная классификация американских линг- вистов легла и в основу работ отечественного лингвиста, Анатолия Прокопьевича Чудинова, при описании политического дискурса, при этом она предоставляет широкую возможность и для художественного дискурса настоящего исследования, так как именно Чудинов в своей классификации предложил антропоморфную и природоморфную метафоры, которые являются основой нашей работы.

Метафорическая модель по А.П. Чудинову - это «существующая и/или складывающаяся в сознании носителей языка схема связи между понятийными сферами, которую можно представить определённой формулой « $X$ - это $Y »[9$, с. 68-71].

А.П. Чудинов дает следующее определение и описание для антропоморфной и природоморфной метафор:

1. Природоморфная метафора. Источниками метафоризации в данном случае служат понятийные сферы «Животный мир», «Мир растений». Иными словами, всякое явление понимается через концепты окружающего человека мира.

2. Антропоморфная метафора. При изучении данного вида анализируются концепты, относящиеся к исходным понятийным сферам «Анатомия и физиология», «Болезнь», «Секс», «Семья» [10, с. 53].

Далее рассмотрим наиболее яркие примеры природоморфной и антропоморфной метафор в романе Ивана Сергеевича Тургенева «Отцы и дети». Опираясь на классификацию А.П. Чудинова, выделим метафорические модели и фреймы в оригинале произведения, а также проанализируем переводы концептуальных метафор и способы их сохранения:

\section{1) МОДЕЛЬ: ЧУВСТВО - ЭТО ЖИВОТНОЕ ФРЕЙМ: АГРЕССИВНОЕ ПОВЕДЕНИЕ ЖИВОТНОГО}

Агафоклея Кузьминишна скоро за ним последовала: она не могла привыкнуть к глухой столичной жизни; тоска отставного существованья ее загрызла [1, с. 2].

Agathokleya Kuzminishna soon followed him; she could not accustom herself to a dull life in the capital; she was consumed by the ennui of existence away from the regiment [11, c. 12].

Англоязычный вариант перевода включает синтаксическое преобразование, в результате которого активный залог был заменен на страдательный. Глагол «загрызла» был передан словосочетанием «consume by», которое можно перевести как «быть поглощенным чем-либо, находиться под контролем кого-либо». Тем не менее, в переводе эмоциональный образ метафоры не был раскрыт полностью в связи с использованием нейтрализации, а метафорическая модель не сохранилась. 
Agathokleia Kuzminischna folgte ihm bald nach; sie konnte sich in das zurückgezogene Leben, das sie in der Hauptstadt nun zu führen hatte, nicht finden. Der Verdruß, sozusagen sich nun selbst in den Ruhestand versetzt zu sehen, führte sie rasch dem Grabe zu [12, c. 3].

В немецкоязычном варианте переводчик использовал прием эмфатизации, которая привела к обратному эффекту. Метафора была передана словосочетанием «dem Grabe zu führen», которое можно перевести дословно «привести в могилу». Переводчику не удалось сохранить метафорическую модель, однако метафорический образ и экспрессивность были не только сохранены, но и усилены.

\section{2) МОДЕЛЬ: ПРИРОДА - ЭТО ЧЕЛОВЕК ФРЕЙМ: СОСТОЯНИЕ ЧЕЛОВЕКА}

...и, вызванный жалким видом обессиленных животных, среди весеннего красного дня вставал белый призрак безотрадной, бесконечной зимы с ее метелями, морозами и снегами $[1$, с. 5].

....and the piteous state of the weak, starved beasts in the midst of the lovely spring day, called up, like a white phantom, the endless, comfortless winter with its storms, and frosts, and snows $[11$, c. 11$]$.

Метафора в английском языке переведена дословно, а слово «безотрадной» с помощью вариантного соответствия «comfortless», что позволило сохранить метафорическую модель и авторский стиль. При передаче метафоры на немецкий язык переводчик использовал аналогичный прием, успешно раскрыв эмоциональный образ метафоры.

...und mitten im Glanz des Frühlings mahnte der Anblick dieser armen Tiere an das weiße Gespenst des endlosen, unbarmherzigen Winters mit seinem Frost und seinen Schneestürmen $[12$, c. 10].

\section{3) МОДЕЛЬ: ПРИРОДА - ЭТО ЧЕЛОВЕК ФРЕЙМ: ДЕЙСТВИЯ ЧЕЛОВЕКА}

а пока он размышлял, весна брала свое. Все кругом золотисто зеленело, все широко и мягко волновалось и лоснилось под тихим дыханием теплого ветерка;...красиво чернея в нежной зелени еще низких яровых хлебов, гуляли грачи $[1$, с. 6];

... but even as he reflected, the spring regained its sway. All around was golden green, all-trees, bushes, grassshone and stirred gently in wide waves under the soft breath of the warm wind;...the rooks strutted among the halfgrown short spring-corn, standing out black against its tender green [11, c. 21];
В английском языке слово «брать» было передано с помощью вариантного соответствия, глагола «regain возвращать», а дополнение «свое» передано существительным «sway - власть, господство» путем экспрессивно-прагматической конкретизации; фраза «grass shone and stirred gently» была передана дословно, наряду с метафорой «in wide waves under the soft breath of the warm wind» при вариантном соответствии «soft - тихий». Основными приемами при передаче данной концептуальной метафоры являются дословный перевод и вариантное соответствие, позволившие сохранить концепт метафоры и метафорическую модель.

Während Arkad hierüber nachdachte, war um ihn her der Lenz in schönster Entwicklung. Überall lichtes Grün: unter dem sanften Atem eines warmen, leichten Windes schwoll und glänzte alles,.......Raben, deren schwarzes Gefieder sich schön von dem zarten Grün der Saaten abhob, ließen sich da und dort sehen $[12$, c. 11];

В немецкоязычном варианте перевода существительное «весна» было передано с помощью вариантного соответствия «der Lenz», глагол «волновалось» переведен глаголом «schwoll - набухать, наполняться» (что можно сказать и о природе-растениях). Метафора «гуляли грачи» передана через синтаксическое преобразование «ließen sich da und dort sehen», что связано с лексико-грамматическими особенностями языка перевода. Метафорическая модель сохранена частично, как и метафорический образ, при этом важно было передать наделение природы человеческими чувствами, что не удалось в полной мере сделать переводчику.

\section{4) МОДЕЛЬ: ПРИРОДА - ЭТО ЧЕЛОВЕК ФРЕЙМ: ОБРАЗ ДЕЙСТВИЯ ЧЕЛОВЕКА}

Ласточки летали высоко; ветер совсем замер; запоздалые пчелы лениво и сонливо жужжали в иветах сирени [1, с. 27];

При передаче метафоры англоязычный переводчик использовал вариантное соответствие, глагол «die away - затихать, ослабевать», а наречие «лениво» было передано с помощью нейтрализации «slowly», что несколько ослабило эмоциональный окрас предложения. Наречие «drowsily» было передано с помощью дословного перевода.

The swallows flew high; the wind had quite died away, belated bees hummed slowly and drowsily among the lilac blossom [11, c. 47];

В переводе на немецкий язык словосочетание «ветер совсем замер» выражено вариантным соответствием «...ganz gelegt», которое можно перевести как «почти полностью утих». Наречие «лениво» было передано с 
помощью вариантного соответствия, «schwach - слабо, болезненно», при этом наречие «сонливо» переведено с помощью буквального перевода «halb verchlafen - в полусне». Переводчик смог сохранить образ и модель метафоры с помощью буквального перевода.

Die Schwalben flogen sehr hoch, der Wind hatte sich fast ganz gelegt; verspätete Bienen summten schwach und halbverschlafen in den Blüten des Fliedergebüsches... [12, c. 49]

\section{МОДЕЛЬ: ОРГАН - ЭТО ЧЕЛОВЕК \\ ФРЕЙМ: ЧУВСТВА ЧЕЛОВЕКА}

\section{МОДЕЛЬ: РАСТЕНИЕ - ЭТО ЧЕЛОВЕК ФРЕЙМ: ЧУВСТВА (ПОВЕДЕНИЕ) ЧЕЛОВЕКА}

Какое бы страстное, грешное, бунтующее сердие ни скрылось в могиле, иветы, растущие на ней, безмятежно глядят на нас своими невинными глазами: не об одном вечном спокойствии говорят нам они, о том великом спокойствии «равнодушной» природы; они говорят также о вечном примирении и о жизни бесконечной... [1, с. 101]

However passionate, sinning, and rebellious the heart hidden in the tomb, the flowers growing over it peep serenely at us with their innocent eyes; they tell us not of eternal peace alone, of that great peace of 'indifferent' nature; tell us too of eternal reconciliation and of life without end [11, c. 151].

В переводе на английский язык эпитеты «страстное, грешное, бунтующее», относящиеся к существительному «сердце», были переведены дословно, что позволило переводчику полностью сохранить метафорическую модель и эмоциональный образ. Персонификация природы, а именно цветов, в приведенной метафоре выражается при помощи полного дословного перевода, что является оправданным шагом со стороны переводчика.

Wie leidenschaftlich, wie rebellisch das Herz auch war, das in einem Grabe ruht, die Blumen, die darauferblühen, sehen uns freundlich mit ihren unschuldigen Augen an; sie erzählen uns nicht allein von der ewigen Ruhe, von der Ruhe der sgleichgültigen« Natur; sie erzählen uns auch von der ewigen Versöhnung und von einem Leben, das kein Ende haben soll [12, c. 184].

В немецкоязычном варианте переводчик применил прием опущения: прилагательное «грешное» не было передано в языке перевода. Основным способом перевода антропоморфной метафоры стал дословный перевод вместе с приемами опущения и вариантного соответствия «безмятежно» - «freundlich» (букв. «дружелюбно, ласково»), что смягчило и несколько нейтрализовало эмоциональный окрас предложения, при этом переводчик смог частично сохранить модель концептуальной метафоры.

В рассмотренных нами примерах основным и наиболее частотным способом передачи природоморфной и антропоморфной метафор стал дословный перевод и вариантное соответствие. Реже встречались прием нейтрализации, конкретизации и опущения/добавления. Использование синтаксического преобразования в немецком языке обусловлено определением порядка слов в зависимости от типа предложения и особенностями построения сложных предложений. Несмотря на сложность передачи метафор в языке оригинала, переводчикам в большинстве случаев удалось сохранить метафорические модели. Перевод концептуальной метафоры требует решения как лингвистических, так и культурологических проблем, а необходимость адекватной передачи метафорического образа и стилистического эффекта обуславливает выбор способа перевода метафоры. В связи с тем, что метафорические системы в анализируемых языка нередко различаются, метафорические образы, характерные для русского языка, могут отсутствовать в языках перевода, поэтому у переводчиков возникает необходимость изменения метафорического образа и модели при сохранении прагматического эффекта.

\section{ЛИТЕРАТУРА}

1. Иван Тургенев «0тцы и дети» [Электронный ресурс]. URL: https://www.100bestbooks.ru/files/Turgenev_0tcy_i_deti.pdf (дата 0бращения 19.04.2021)

2. Казакова, Т. А. Практические основы перевода. English - Russian / Т.А. Казакова. - СПб.: Издательство Союз, 2001. - 265 с.

3. Краткий словарь когнитивных терминов [Текст] / Е.С. Кубрякова [и др.]. - М.: Изд-во МГУ, 1996. - 247 с.

4. Курбанов И.А., Носкова С.Г. Антропоморфные метафоры в моделировании образа человека с ограниченными возможностями в дискурсе российских и американских СМИ. Общественные науки. 2015. № 6-1. С. 126-134.

5. Курбанов И.А., Носкова С.Г. Природоморфные метафоры в дискурсе инвалидности российских и американских СМИ. Вестник Российского университета дружбы народов. Серия: Русский и иностранные языки и методика их преподавания. 2016. № 2. С. 57-62.

6. Лакофф, Дж., Джонсон, М. Метафоры, которыми мы живем: Пер. с англ. / Под ред. и с предисл. А.Н. Баранова. - М.: Едиториал УРСС, 2004. - 256 с.

7. Никитина, С.Е. Языковое сознание и самосознание личности в народной культуре. Язык и личность [Текст] / С.Е. Никитина. - М.: Наука, 1989. - С. 34-40.

8. Тарасова, И.А. Когнитивная поэтика в лингвокультурологической перспективе [Текст] / И.А. Тарасова // Языковое бытие человека и этноса: психолингвистические когнитивные аспекты. - М., 2003. - С. 77.

9. Чудинов А.П. Метафорическая мозаика в современной политической коммуникации: Монография / Урал. гос. пед. ун-т. — Екатеринбург, 2003. — 248 с. 
10. Чудинов А.П. Россия в метафорическом зеркале: Когнитивное исследование политической метафоры (1991—2000): Монография / Урал. гос. пед. ун-т. — Екатеринбург, 2001. — 238 c.

11. Fathers and Sons. Ivan Turgenev (English) [Электронный ресурс]. URL: http://originalbook.ru/download/T/Turgenev/0D/Turgenev,\%20lvan\%20-\%20Fathers\%20 and\%20Sons_en.epub (дата обращения 19.04.2021)

12. Väter und Söhne. Iwan Turgenew (Deutsch) [Электронный ресурс]. URL: http://originalbook.ru/download/T/Turgenev/0D/Vater\%20und\%20Sohne\%20-\%20 Iwan\%20Sergejewitsch\%20Turgenew_de.fb2 (дата обращения 19.04.2021)

(с Курбанов Ибрагим Алиевич (ibragimkurbanov@mail.ru), Фурзиков Илья Евгеньевич (Ilya_furzikov@mail.ru)

Журнал «Современная наука: актуальные проблемы теории и практики»

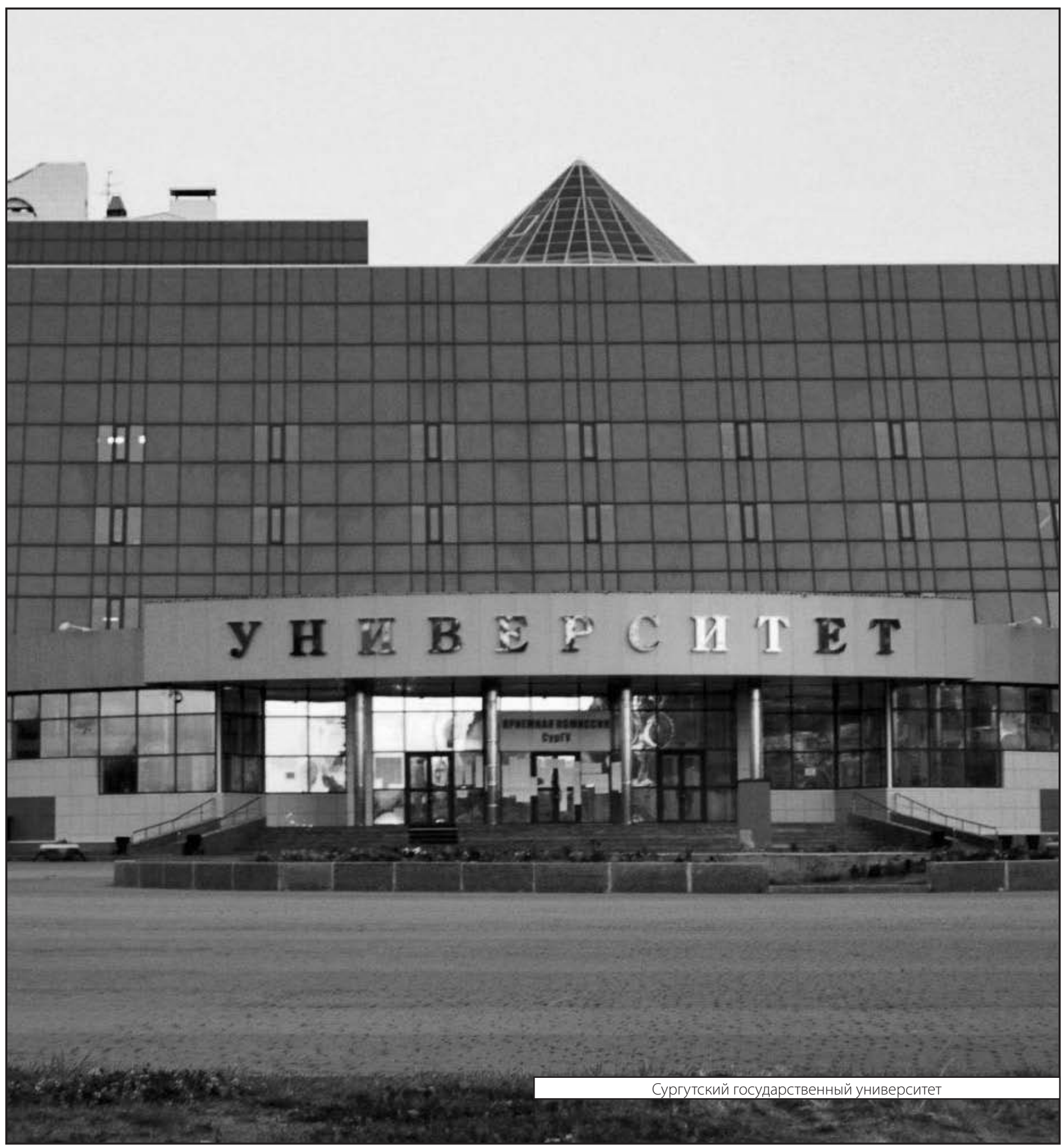

